\title{
The effect of conventional $v$. à la carte menu on energy and macronutrient intake among hospitalized cardiology patients
}

\author{
Camilla S. Larsen and Søren Toubro* \\ Department of Clinical Nutrition 225, Hvidovre Hospital, Kettegaards Allé 30, DK-2650 Hvidovre, Copenhagen \\ University, Denmark
}

(Received 25 August 2006 - Revised 1 February 2007 - Accepted 16 February 2007)

\begin{abstract}
Undernutrition among hospitalized patients is highly prevalent. In contrast, the obesity pandemic is increasing in prevalence among all, including cardiology patients. The dietary challenge during hospitalization is to provide a healthy diet that stimulates the appetite and is suitable for both patients at risk of undernutrition and of cardiovascular events. The aim of the present study was to compare energy and macronutrient intake between a conventional hospital menu (Fixed) with a concept providing free serving hours and ad libitum intake à la carte (Free) among cardiology patients. The comparison was done between concepts for all lean $\left(\mathrm{BMI}<25 \mathrm{~kg} / \mathrm{m}^{2}\right)$ and overweight and obese $\left(\mathrm{BMI} \geq 25 \mathrm{~kg} / \mathrm{m}^{2}\right) \mathrm{patients}$ and subgroups. Food intake was registered during a 3-week period on Fixed for forty-eight randomly selected patients and later by two similar time periods on Free1 for twenty-eight and Free2 for thirty-seven other patients. Free compared with Fixed increased the energy intake - but not above requirement - among the obese only $(P<0.001$; Free $v$. Fixed). This was explained by an increase in the relative fat intake of $50 \%$ $(P<0.001)$ and $37 \%(P<0.001)$ for Free1 and Free2 respectively. During Free1, the relative fat intake correlated positively with BMI $(r$ 0.6; $P<0.01)$, and the relative carbohydrate intake negatively with BMI $(r-0.7 ; P<0.01)$; the same pattern was seen during Free2, although insignificant. We conclude that the introduction of an ad libitum à la carte kitchen (Free) to cardiology patients slightly increases the average nutritional intake, but contains a potential health hazard for overweight cardiovascular patients, due to the selection of high-fat dishes and decreased carbohydrate intake. This emphasises the need for improvement in fat sources and in dietary advice when an ad libitum concept is applied during hospitalization.
\end{abstract}

Cardiology patients: Fat intake: Hospital menus

Undernutrition among hospitalized patients is highly prevalent and in focus ${ }^{1,2}$ in Denmark ${ }^{3,4}$, and associated with morbidity and mortality ${ }^{5,6}$. However, in spite of the high focus on undernutrition during hospitalization, it is important not to ignore the increasing prevalence of obesity in cardiology patients. Among cardiology patients - independently of their actual weight $-10-30 \%$ will be diagnosed as undernourished and treated as such, whereas up to $80 \%$ are overweight or obese ${ }^{7}$.

Diet is a major modifiable risk factor for morbidity and mortality especially for cardiovascular patients, with or without overweight. A comprehensive tertiary prevention strategy to reduce cardiac events includes a diet rich in vegetables, fruits, grains and polyunsaturated fat and low in saturated $\mathrm{fat}^{8-10}$. The official Danish nutritional guidelines for institutions recommend a macronutrient composition of $18 \%$ energy from protein, $40 \%$ energy from fat and $42 \%$ energy from carbohydrate and for well-nourished diabetic, obese or cardiovascular patients of $10-15 \%$ energy from protein, $30 \%$ energy from fat and 55-60\% energy from carbohydrate. For undernourished patients up to $50 \%$ energy from fat is recommended $^{11}$. This illustrates the challenge in composition and availability for the hospital food supply.
Several non-blinded single intervention studies have reported that energy intake in hospitalized patients or individuals in nursing homes can be stimulated by improving the social ambience ${ }^{12}$, flavouring the food ${ }^{13}$, introducing menu choices $^{14}$, improving the patient care ${ }^{15}$ and changing the energy density of different meals ${ }^{16}$. But comparative dietary intervention studies during hospitalization are rare $^{14}$, and none have investigated how different menus affect dietary intake among cardiology patients.

A recent study of in-house patients at Hvidovre Hospital (Copenhagen, Denmark) found that despite a plentiful food supply from the conventional hospital kitchen (the same as Fixed menu in the present study), patients only on average had $60 \%$ of their energy needs covered ${ }^{17}$. In order to reduce the potential risk of insufficient nutrient intake, a new à la carte concept (Free) was introduced as an alternative to the conventional more fixed hospital serving (Fixed). The aim of the present study was therefore to investigate if a new à la carte concept would influence the energy intake and macronutrient intake among cardiology patients in general and in relation to their BMI.

Abbreviations: Fixed, conventional hospital menu diet; Free, à la carte menu diet; Free1, Free diet trial period 1; Free2, Free diet trial period 2.

* Corresponding author: Associate Professor Søren Toubro, fax +45 3632 3789, email st@life.ku.dk 


\section{Methods}

A pilot study introducing the à la carte menu was conducted from August 2004 to May 2005 at four different departments (the orthopaedic, the gynaecological, the obstetric and the cardiology ward) with approximately 150 beds in total. This paper presents a comparison between the two dietary concepts done at the Department of Cardiology with about thirty-five beds in total.

\section{The hospital}

Hvidovre Hospital is a University Hospital with 700 beds located in the southern suburb of Copenhagen. At admission to Hvidovre Hospital, the patients' nutritional state is evaluated within the first $24 \mathrm{~h}$ based on the European Society of Parenteral and Enteral Nutrition (ESPEN) screening score method $^{18}$, where BMI, recent weight loss and dietary intake before admission, and severity of disease are included as determining factors. Patients receive nutritional therapy, including energy-enriched meals, protein drinks, diets with reduced salt content etc, based on the result of the nutritional screening.

\section{Conventional hospital menu}

All patient dishes for the conventional hospital menu (Fixed) were produced in a central kitchen. The staff included approximately 100 full-time employees headed by a catering officer. All meals were dispatched to the departments at fixed hours. The standard servings consisted of three meals, and were planned and nutritionally calculated by catering officers on a weekly basis $14 \mathrm{~d}$ before production. Breakfast and lunch were served at the department as a buffet including four to seven different alternatives, whereas supper was served in fixed sizes on a single tray for each patient. Snacks and between-meal food included bread, fruit and cakes and were available on request at each department.

The average daily price for raw food material per patient was in the order of $20 \mathrm{DKK}(€ 2 \cdot 80)$ and the production cost in the order of 100 DKK $(€ 14)$.

The food production was aiming at being in accordance with the official Danish nutritional guidelines for institutions, where breakfast and supper each should constitute $20-25 \%$ of the daily energy requirement, lunch should constitute 25$30 \%$, and up to $35 \%$ could be covered by between-meal food or snacks ${ }^{11}$.

\section{À la carte menu}

Based on inspiration from gourmet restaurants and guided by a chef, an à la carte kitchen was established at the hospital. A staff of thirteen individuals headed by the chef produced all dishes. All food items were listed in a coloured menu card, distributed among the patients. Patients ordered the dishes themselves, using a phone installed at each hospital bed. If the patients were physically or mentally unable to order, the nursing staff assisted. Kitchen staff at a call centre received, handled and passed the orders by a monitor screen to the production team. At the call centre, the patients' data (name, bed, department and diagnosis), together with nutritional status and any dietary restrictions, were visualized at a computer screen. The kitchen staff could guide, but the patients were free to order as they liked. The à la carte kitchen was operative between 07.00 and 20.00 hours. Immediate orders were served within $45 \mathrm{~min}$. Orders could be placed up to $24 \mathrm{~h}$ in advance.

The menu card included almost 100 different food items including breakfast, lunch and supper dishes, fruits and desserts. Soft drinks and juice were available from the ward.

Food items or meals with $\geq 50 \%$ energy from fat were marked with a red asterisk in the menu card, indicating by text that these dishes were recommended for undernourished patients only. The average daily price for raw food material per patient was in the order of 23 DKK (€3.20) and with production costs similar to the conventional hospital menu.

\section{Patients}

During both concepts, sixteen beds from a potential total of thirty-five beds distributed at eight one-bed rooms, four twobed rooms and four four-bed rooms at the Department of Cardiology were chosen as a starting point for registration of the patients' nutrient intake. These beds were distributed as four one-bed rooms, two two-bed rooms and four fourbed rooms; this randomization tended toward registration of a higher number of undernourished patients, because the one-bed rooms preferentially are chosen for the most critically ill patients. The patients were followed from admission to discharge; patients were also followed if they were moved to another bed at the Department of Cardiology. Only data from patients hospitalized for a minimum of one full day were included. When a new admitted patient was stationed in the discharged patient's bed, this new patient was enrolled in the study and food intake consequently registered.

Information about age, sex, weight, height, diagnosis, nutritional state and period of hospitalization was obtained from the patients' health records. If some of these data were missing, the patient or staff were asked or the weight and height were estimated by one of the authors. If the patient was weighed more than once, all weight data were noted. Analyses were done for all patients and separated into groups of nonobese patients with $\mathrm{BMI}<25 \mathrm{~kg} / \mathrm{m}^{2}$, and overweight or obese patients with $\mathrm{BMI} \geq 25 \mathrm{~kg} / \mathrm{m}^{2}$. ${ }^{19}$

\section{Study registration periods}

Patients energy and macronutrient intake was recorded for a 3-week period during Fixed (16 August to 5 September 2004) and for a 3-week period during Free (Free1 from 18 October to 7 November 2004) and a 4-week period during Free (Free 2 from 31 January to 28 February 2005). There were two registration periods on Free in order to investigate if there were any differences in patients' nutrient intake during the initial and later period of the pilot project. The second period during Free was extended by 1 week, due to a low number of admitted patients and thereby a low number of registrations. 


\section{Registration of nutrient intake}

Staff and all patients included in the study were informed that the registration was done in order to measure energy intake during hospitalization. They were instructed to carefully register their daily nutrient intake on a pre-designed A4 paper form with time of day, description and amounts of food served, eaten, and left, including hospital meals and drinks, items bought in the hospital shop and items brought in by family or friends. If the patients were unable to register themselves, the hospital staff or family assisted. All registrations were collected daily by one of the authors. If incomplete, information was gathered by one of the authors from the patient or staff, or if not possible this specific registration was excluded from further analysis. To check if the patients' registrations were in agreement with the actually served meals, menu plans from the hospital kitchen during Fixed, and telephoned orders from the call centre's computer during Free were used. If not, the registration was excluded.

The hospital kitchen calculated energy and macronutrient contents of all dishes served during Fixed, by using the nutritional software program Dankost $200{ }^{\circledR}$ (Dansk Catering Center A/S, Herlev, Denmark). The authors also used this program to calculate nutrient contents of meals from the menu card, and patients' daily nutrient intakes during both concepts. Patients' daily energy requirements were estimated by the Schofield equation as $\mathrm{BMR} \times 1.3$, corresponding to the energy expenditure for inactive individuals ${ }^{20}$. Mean nutrient intake was calculated for each patient during his or her admission and for all patients during each of the three periods. The calculated daily energy requirement and registered energy intake were used to measure patients' daily coverage of energy.

\section{Validation of servings}

Portion sizes and composition of the served meals during both concepts were validated by random sampling. From the Department of Cardiology we collected seven and six different meals during Fixed and Free, respectively. This was organized single-blinded for the staff both in the kitchen, and at the department, where orders were placed for a dummy patient. We divided the selected meals into food components, weighed each of these separately, and calculated the actually energy and macronutrient content by using the Dankost $2000^{\circledR}$ (Dansk Catering Center A/S).

\section{Statistical methods}

All statistical analyses were performed using the Statistical Package for the Social Sciences (SPSS 11.5 for Windows; SPSS Inc., Chicago, IL, USA). Results are given as mean values and standard deviations. The Student's unpaired $t$ test was used to determine any group differences between Fixed and Free1, and Fixed and Free2. Differences in energy and macronutrient intake for both normal-weight and overweight patients were tested by analysis of covariance, including body weight as covariate. Correlations were performed for macronutrient intake and BMI. $P<0.05$ was considered statistically significant.

\section{Ethical consideration}

As this was a register study, informed consent was not obtained. This procedure was confirmed by the ethics committee before the study start.

\section{Results}

In total, we collected 304 dietary intake registration forms from seventy patients during Fixed, 189 registrations from forty-three patients during Free1 and 244 from sixty-five patients during Free2. Due to incomplete registrations, hospitalization for less than $1 \mathrm{~d}$, or patient transferred to other wards, the dataset was reduced to 225,137 and 164 registrations distributed between forty-eight, twenty-eight and thirty-seven patients, respectively. There was a relatively large range in length of time of registration, but no significant differences were found between the three periods. During each registration period the following number of patients had more than $3 \mathrm{~d}$ of registration: twenty-seven during Fixed, eighteen during Free1, and twenty-six during Free2 (group difference NS). No association between energy intake or macronutrient composition and duration of the registration period was found.

We had to estimate body weight mainly by self-report for six patients $(12 \%)$ during Fixed, two $(7 \%)$ during Free1 and none during Free2 (group difference NS). Acute myocardial infarction was the dominant diagnosis among all patients (27\% during Fixed, $32 \%$ during Free1 and 24\% during Free2). Other prevalent diagnoses were atrial flutter, angina and pneumonia. At inclusion $10-15 \%$ of all patients were at nutritional risk according to ESPEN guidelines ${ }^{18}$ and therefore encouraged during Free to choose meals with higher energy content and during Fixed were served meals with a higher fat content. Further, they were encouraged by the nursing staff during both concepts to drink protein drinks as nutritional therapy. None of the patients had restricted intake of salt. We do not have data on the progression of patients' illnesses, nutritional status or weight changes during the registration periods. Table 1 shows anthropometry and energy intake during Fixed, Free1 and Free2 for all patients.

Age, anthropometry and the mean number of registrations per subject were well matched for all three periods. There was a tendency towards a higher body weight during Free1 and Free2 compared with Fixed. Patients had a significant higher energy intake during Free2 (7.9 (SD 2.0) MJ) compared with Fixed (6.6 (SD 2.0) MJ) $(P<0.01)$, which disappeared after adjustment for differences in body weight. Based on Schofield's equation and a physical activity level of 1.3 the energy intake covered 86 (SD 27) \% estimated requirement during Fixed, 89 (SD 29) \% during Free1 and 101 (SD 25) \% during Free2 $(P<0.01$ for Fixed $v$. Free2). Coverage below $75 \%$ energy requirement was true for $35 \%$ of the patients during Fixed v. $29 \%$ during Free1 and $16 \%$ during Free2 (group difference, NS). The relative fat intake was higher, and the relative carbohydrate energy content correspondingly lower both during Free1 (41\% fat and $43 \%$ carbohydrate), and Free2 (41 and 42\%) compared with Fixed (32 and $51 \%)(P<0.001$ for both).

Forty-eight percent during Fixed, $46 \%$ during Free1 and $49 \%$ of all patients during Free 2 were males (NS). We found no sex effect on energy or macronutrient intake 
Table 1. Anthropometry and energy intake for all patients during each of the three registration periods (Fixed, Free1 and Free2) $\dagger$

(Mean values and standard deviations)

\begin{tabular}{|c|c|c|c|c|c|c|}
\hline & \multicolumn{2}{|c|}{$\begin{array}{l}\text { Fixed } \\
(n 48)\end{array}$} & \multicolumn{2}{|c|}{$\begin{array}{l}\text { Free1 } \\
(n 28)\end{array}$} & \multicolumn{2}{|c|}{$\begin{array}{l}\text { Free2 } \\
(n 37)\end{array}$} \\
\hline & Mean & SD & Mean & SD & Mean & SD \\
\hline \multicolumn{7}{|l|}{ Sex } \\
\hline Males $(n)$ & & 23 & & 13 & & 18 \\
\hline Females $(n)$ & & 25 & & 15 & & 19 \\
\hline Age (years) & 75 & 16 & 73 & 13 & 71 & 16 \\
\hline $\begin{array}{l}\text { Registrations } \\
\text { period (d) }\end{array}$ & 5 & 5 & 5 & 4 & 4 & 3 \\
\hline Body weight (kg) & 71.8 & $15 \cdot 2$ & 78.9 & $22 \cdot 8$ & 74.6 & $16 \cdot 4$ \\
\hline $\mathrm{BMI}\left(\mathrm{kg} / \mathrm{m}^{2}\right)$ & $25 \cdot 3$ & 3.9 & $27 \cdot 2$ & $5 \cdot 6$ & $25 \cdot 7$ & 4.9 \\
\hline Energy intake (MJ/d) & $6 \cdot 6$ & $2 \cdot 0$ & $7 \cdot 2$ & $2 \cdot 4$ & $7 \cdot 9^{\star *}$ & $2 \cdot 0$ \\
\hline Protein (\% energy) & 18 & 4 & 17 & 2 & 17 & 2 \\
\hline Fat (\% energy) & 32 & 8 & $41^{\star \star \star}$ & 10 & $41^{\star \star \star}$ & 7 \\
\hline $\begin{array}{r}\text { Carbohydrate } \\
(\% \text { energy })\end{array}$ & 51 & 8 & $43^{\star \star \star}$ & 10 & $42^{\star \star *}$ & 7 \\
\hline $\begin{array}{l}\text { Energy/body weight } \\
\qquad(\mathrm{kJ} / \mathrm{kg})\end{array}$ & $96 \cdot 3$ & 37 & $95 \cdot 3$ & 34 & 109.8 & 29 \\
\hline
\end{tabular}

Mean value is significantly different from that during Fixed: ${ }^{* \star} P<0.01,{ }^{\star \star *} P<0.001$ (Student's unpaired $t$ test).

†For details of registration periods, see Methods.

during any of the three registration periods after adjustment for differences in body weight except during Free 2 where males tended to have a higher fat intake (44\% energy from fat) compared with $38 \%$ energy from fat in females $(P=0 \cdot 08)$. Table 2 shows anthropometry and energy intake for patients with $\mathrm{BMI}<25 \mathrm{~kg} / \mathrm{m}^{2}$ during Fixed, Free1 and Free2.

Forty-two percent of the Fixed patients, $42 \%$ of the Free1 patients and $43 \%$ of the Free 2 patients had a BMI $<25 \mathrm{~kg} /$ $\mathrm{m}^{2}$ (NS). The relative fat intake was higher and carbohydrate

Table 2. Anthropometry and energy intake for patients with $\mathrm{BMI}<25$ $\mathrm{kg} / \mathrm{m}^{2}$ during each of the three registration periods (Fixed, Free1 and Free2)†

(Mean values and standard deviations)

\begin{tabular}{|c|c|c|c|c|c|c|}
\hline & \multicolumn{2}{|c|}{$\begin{array}{l}\text { Fixed } \\
(n 20)\end{array}$} & \multicolumn{2}{|c|}{$\begin{array}{l}\text { Free1 } \\
(n 12)\end{array}$} & \multicolumn{2}{|c|}{$\begin{array}{l}\text { Free2 } \\
(n 16)\end{array}$} \\
\hline & Mean & SD & Mean & SD & Mean & SD \\
\hline \multicolumn{7}{|l|}{ Sex } \\
\hline Males $(n)$ & & 9 & & 3 & & 8 \\
\hline Females $(n)$ & & 11 & & 9 & & 8 \\
\hline Age (years) & 79 & 15 & 82 & 7 & 77 & 17 \\
\hline $\begin{array}{l}\text { Registrations } \\
\text { period (d) }\end{array}$ & 5 & 5 & 6 & 4 & 5 & 4 \\
\hline Body weight (kg) & $59 \cdot 9$ & $10 \cdot 8$ & $59 \cdot 8$ & $11 \cdot 6$ & $61 \cdot 7$ & $12 \cdot 2$ \\
\hline BMI $\left(\mathrm{kg} / \mathrm{m}^{2}\right)$ & $21 \cdot 6$ & $2 \cdot 6$ & $21 \cdot 7$ & $2 \cdot 1$ & $21 \cdot 3$ & $3 \cdot 1$ \\
\hline Energy intake (MJ/d) & $7 \cdot 3$ & $2 \cdot 2$ & $6 \cdot 6$ & 2.9 & $7 \cdot 2$ & 1.5 \\
\hline Protein (\% energy) & 15 & 3 & 15 & 1 & 16 & 2 \\
\hline Fat (\% energy) & 34 & 8 & 36 & 9 & $42^{\star \star}$ & 7 \\
\hline $\begin{array}{r}\text { Carbohydrate } \\
\text { (\% energy) }\end{array}$ & 51 & 8 & 49 & 9 & $42^{\star \star}$ & 7 \\
\hline $\begin{array}{l}\text { Energy/body weight } \\
(\mathrm{kJ} / \mathrm{kg})\end{array}$ & $125 \cdot 1$ & 36 & $109 \cdot 7$ & $42 \cdot 0$ & 119.5 & $27 \cdot 6$ \\
\hline
\end{tabular}

Mean value is significantly different from that during Fixed: ${ }^{\star \star} P<0.01$ (Student's unpaired $t$ test).

†For details of registration periods, see Methods. lower during Free2 compared with Fixed ( $P<0.01$ for both). Table 3 shows anthropometry and energy intake for patients with BMI $\geq 25 \mathrm{~kg} \mathrm{~kg} / \mathrm{m}^{2}$ during Fixed, Free1 and Free2.

Patients with $\mathrm{BMI} \geq 25 \mathrm{~kg} / \mathrm{m}^{2}$ were equally distributed during the three periods, i.e. $58 \%$ during Fixed, $57 \%$ during Free1 and $57 \%$ during Free2. During Free1 the energy intake was $7.7 \mathrm{MJ}$ and during Free2 $8.5 \mathrm{MJ}$ compared with 6.0 MJ during Fixed $(P<0.001)$. This difference was maintained after adjustment for differences in body weight with a $12 \%$ (NS) higher energy intake during Free1 and 35\% during Free2 compared with fixed $(P<0 \cdot 001)$. The energy intake covered 74 (SD 19) \% of the estimated requirement during Fixed, 84 (SD 29) \% during Free1 and 100 (SD 27) \% during Free2 $(P<0.001$ for Fixed $v$. Free2).

The macronutrient composition of the diets was again different, with lower fat intake and higher carbohydrate intake during Fixed compared with Free1 $(P<0.001$ for both).

Associations between BMI and nutrient intake during Fixed, Free1 and Free2

There was a positive association between BMI and the relative fat intake and a corresponding negative association between BMI and relative carbohydrate intake only during Free1 for all patients (Fig. 1). This finding was more pronounced among the overweight patients, indicated by an $r 0.51 \mathrm{v} . r$ 0.27 for fat intake $(P<0.01)$ and $r-0.52 v . r-0.27$ for carbohydrate intake $(P<0 \cdot 01)$ for lean and obese patients, respectively.

We found no time effect illustrated by group differences between Free 1 and Free 2 in either energy or macronutrient intake.

Calculation on the seven dishes from Fixed showed a CV\% of $6 \%$ for energy content $(\mathrm{kJ}), 8 \%$ for protein, $4 \%$ for fat and $9 \%$ for carbohydrate compared with recipe calculations. The

Table 3. Anthropometry and energy intake for patients with $\mathrm{BMI} \geq 25$ $\mathrm{kg} \mathrm{m}^{2}$ during each of the three registration periods (Fixed, Free1 and Free2)†

(Mean values and standard deviations)

\begin{tabular}{|c|c|c|c|c|c|c|}
\hline & \multicolumn{2}{|c|}{$\begin{array}{l}\text { Fixed } \\
(n 28)\end{array}$} & \multicolumn{2}{|c|}{$\begin{array}{l}\text { Free1 } \\
(n 16)\end{array}$} & \multicolumn{2}{|c|}{$\begin{array}{l}\text { Free2 } \\
(n 21)\end{array}$} \\
\hline & Mean & SD & Mean & SD & Mean & SD \\
\hline \multicolumn{7}{|l|}{ Sex } \\
\hline Males $(n)$ & & 14 & & 10 & & 10 \\
\hline Females $(n)$ & & 14 & & 6 & & 11 \\
\hline Age (years) & 73 & 13 & 67 & 3 & 67 & 15 \\
\hline $\begin{array}{l}\text { Registrations } \\
\text { period }(\mathrm{d})\end{array}$ & 4 & 5 & 4 & 4 & 4 & 3 \\
\hline Body weight (kg) & $80 \cdot 3$ & $12 \cdot 2$ & $93 \cdot 3^{\star *}$ & $18 \cdot 0$ & 84.4 & $11 \cdot 7$ \\
\hline BMI $\left(\mathrm{kg} / \mathrm{m}^{2}\right)$ & $27 \cdot 9$ & $2 \cdot 4$ & $31 \cdot 3^{\star \star \star}$ & 3.5 & $29 \cdot 1$ & $3 \cdot 2$ \\
\hline $\begin{array}{l}\text { Energy intake } \\
\qquad(\mathrm{MJ} / \mathrm{d})\end{array}$ & $6 \cdot 0$ & $1 \cdot 8$ & $7 \cdot 7^{\star \star}$ & 1.9 & $8 \cdot 5^{\star \star \star}$ & $2 \cdot 1$ \\
\hline Protein (\% energy) & 19 & 3 & 18 & 3 & 18 & 2 \\
\hline Fat (\% energy) & 30 & 7 & $45^{\star \star \star}$ & 8 & $41^{\star \star \star}$ & 6 \\
\hline $\begin{array}{r}\text { Carbohydrate } \\
\text { (\% energy) }\end{array}$ & 51 & 7 & $37^{\star \star \star}$ & 9 & $41^{\star \star \star}$ & 7 \\
\hline $\begin{array}{l}\text { Energy/body weight } \\
\qquad(\mathrm{kJ} / \mathrm{kg})\end{array}$ & $75 \cdot 7$ & 22 & 84.5 & 23 & $102 \cdot 4^{\star \star \star}$ & 29 \\
\hline
\end{tabular}

Mean value is significantly different from that during Fixed: ${ }^{\star \star} P<0.01,{ }^{\star \star \star} P<0.001$ (Student's unpaired $t$ test).

†For details of registration periods, see Methods. 

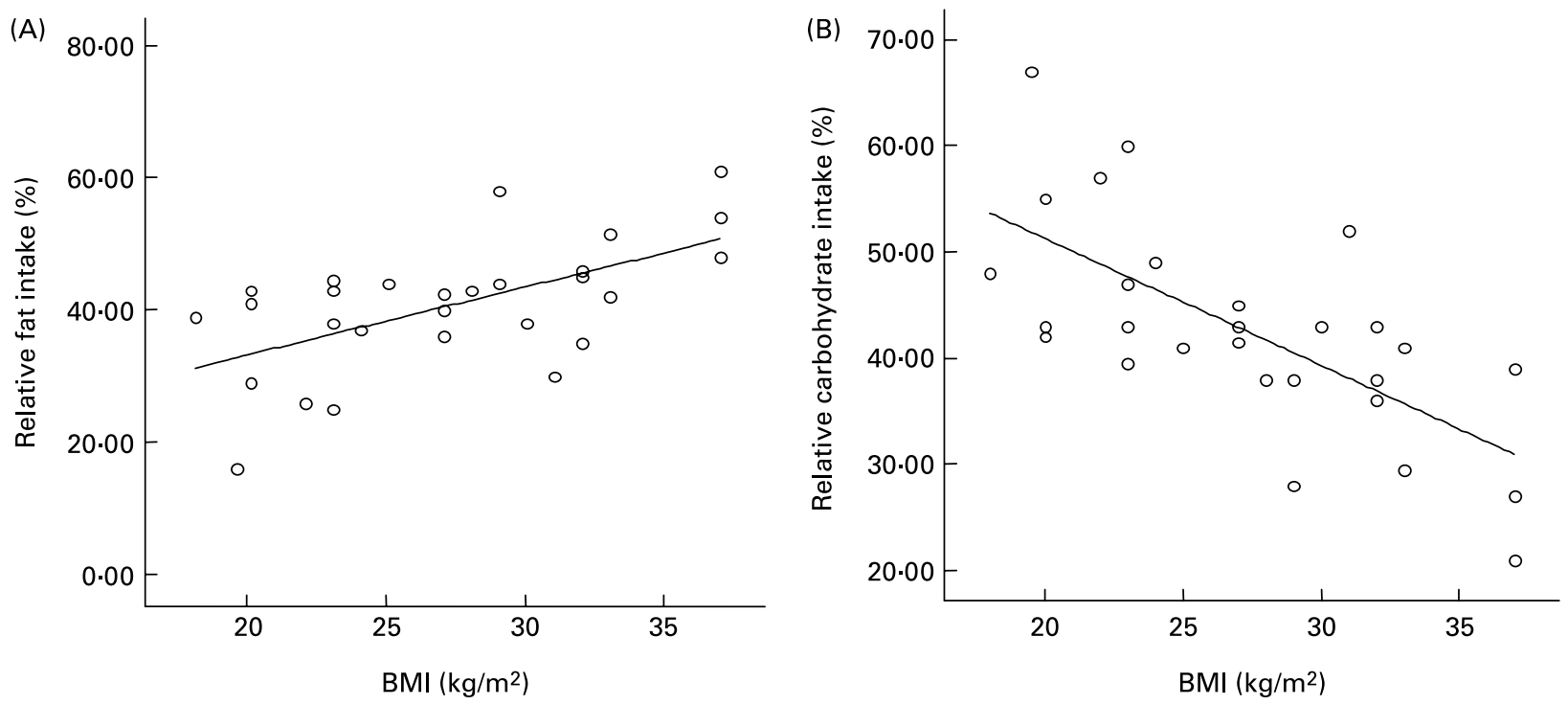

Fig. 1. Correlations between patients' relative fat $(\mathrm{A})(r \quad 0.6 ; P=0.01)$ and carbohydrate $(\mathrm{B})(r-0.7 ; P=0.01)$ intake and $\mathrm{BMI}$ during Free1. For details of registration period Free1, see Methods.

corresponding values for the six dishes during Free showed a $\mathrm{CV} \%$ of $4 \%$ for energy content, $7 \%$ for protein and fat, and $12 \%$ for carbohydrate.

\section{Discussion}

We have compared the energy and macronutrient intake among cardiology patients when served either a fixed conventional hospital menu or an à la carte menu. Independent of sex we found that the à la carte menu significantly increased energy intake but mainly among the obese. The mean energy intake did not exceed energy requirements using Schofield's equation for BMR and a relatively low activity factor of $1 \cdot 3$, still leaving between 15 and $30 \%$ of all patients with an energy intake below $75 \%$ of requirements. The access to fatty dishes increased the mean fat intake by $25-40 \%$ energy from fat and by $40-50 \%$ among the obese patients. This was confirmed by a positive association between relative fat intake and BMI and a reverse association between carbohydrate and BMI, and most pronounced for the obese patients.

Inclusion of patients via the selection of beds mainly in oneand two-bed rooms was estimated to increase the number of patients at nutritional risk. It was therefore a surprise that only $10-15 \%$ of all patients during the three periods were screened to be at nutritional risk.

Johansen et al. reported that only $36 \%$ of Danish in-house patients had a coverage $\geq 75 \%$ of their daily energy requirement $^{21}$. Commonly cited reasons for not eating all the served hospital food have been absence of choices, improper mealtime, inadequate taste ${ }^{22}$, portion size, food consistency and temperature $^{23}$. Therefore, when optimising the food procedure, an individualized provision of meals should be included $^{15}$, where patients are eventually involved in planning of meals, and have the possibility to order dishes ${ }^{24}$. Other intervention studies have confirmed an increased nutrient intake when challenging the standard hospital menu, with flavour $^{13}$ and energy ${ }^{16}$, or offering choices of energy-enriched side orders or snacks to the normal hospital menu ${ }^{25}$. A Danish study including patients at risk of undernutrition reported that introducing a choice between two main menus increased the energy and protein intake by 23 and $17 \%$ respectively ${ }^{14}$. These recommendations are integrated into the new à la carte kitchen at Hvidovre Hospital, where patients' self-selection of what and when to eat has been expanded. A study at Hvidovre Hospital from the year 2000, including patients with or without undernutrition, found that the mean intake during the Fixed menu system covered $60-70 \%$ of the daily energy requirement estimated by Schofield ${ }^{17}$. This has now according to the present study increased to $86 \%$ and 5$10 \%$ more by applying the flexible menu concept Free, but witnesses the importance of continuous focus on dietary intake, as between 15 and $30 \%$ of our cardiology patients did not have an intake that exceeded $75 \%$ of their requirements. Registration of the patients' nutrient intake is supposed to influence the staff by increasing their awareness and thereby encouraging the patients either to eat more, or to register a higher intake. This phenomenon is expected to be a potential confounder across studies, but not in the present study as nursing staff and the methods of registrations were identical during all three periods, and no time effect was found between Free1 and Free2.

Macronutrient recommendations in Denmark for well-nourished cardiology in-house patients are similar to the general recommendations for free-living subjects with a relative macronutrient distribution of $10-15 \%$ energy from protein, $30 \%$ energy from fat, and 55-60\% energy from carbohydrate $^{11}$. On average, all patients during Fixed had a higher protein intake, a suitable fat intake and a slightly lower carbohydrate intake than these recommendations; however, the macronutrient composition during Free1 and Free2 was more in accordance with the institutional guidelines of $18 \%$ energy from protein, $40 \%$ energy from fat and $42 \%$ energy from carbohydrate. 
As mentioned in the Introduction, preventative treatment of cardiac events and overall mortality includes a diet rich in vegetables, fruits, grains and polyunsaturated fat and low in saturated fat. But despite this, many cardiology patients are still lacking sufficient knowledge of a proper $\operatorname{diet}^{26,27}$. The present study supports this lack of knowledge, by showing that a free choice of meals including fatty food items promote fat intake and that this was positively associated with BMI. This underlines the importance for hospitals in general to be strong proponents for a preventable lifestyle, during a period where it has been shown possible for the staff to improve the patients' awareness of cardiovascular risk factors ${ }^{27,28}$, Also, assistance with choice of food is not only imperative to prevent undernourished patients from choosing foods which are inadvisable with respect to their clinical condition ${ }^{24}$, but also for the overweight cardiology patients. The fatty food items from the à la carte menu mostly consisted of saturated fat from meat, cream and butter. These are also modifiable factors that contribute to a deleterious health effect.

The mean age of our cardiology patients was above 70 years. It is highly possible that our findings are relevant for patients with other diagnoses and younger age but that has to be confirmed by others, as the prevalence of obesity is increasing in all age groups and leads to a higher prevalence of $\mathrm{CVD}^{29}$.

Unfortunately, the short mean period of hospitalization and the limited number of patients did not justify analysis on the development of the patients' nutritional status during hospitalization or differences, if there were any, depending on the actual diagnosis.

We conclude that the introduction of an ad libitum à la carte kitchen to cardiology patients slightly increases the average nutritional intake, but contains a potential health hazard for overweight cardiovascular patients, due to the selection of high-fat dishes and decreased carbohydrate intake. This emphasises the need for improvement in fat sources and in dietary advice when an ad libitum concept is applied during hospitalization.

\section{Acknowledgements}

The source of funding was Hvidovre Hospital. There was no conflict of interest. Both authors have contributed to the planning of the project, the introducing of the registration methods to the nursing staff and patients, and the collecting of registrations. The first author performed the analyses and both authors were responsible for the writing of the manuscript. We thank the staff at the Department of Cardiology, including Head Nurse Gytha Christensen for assistance with filling in the patients' daily registrations of nutrient intake. Furthermore, thanks to the central kitchen staff including Head Elinor Nielsen and Chef Mogens Fonseca Pedersen from the à la carte kitchen.

\section{References}

1. McWhirter JP \& Pennington CR (1994) Incidence and recognition of malnutrition in hospital. BMJ 308, 945-948.

2. Waitzberg DL, Caiaffa WT \& Correia MITD (2001) Hospital malnutrition: The Brazilian National Survey (IBRANUTRI): a study of 4000 patients. Nutrition 17, 573-580.
3. Kondrup J, Johansen N, Plum LM, Bak L, Larsen IH, Martinsen A, Andersen JR, Bærnthsen H, Bunch E \& Lauesen N (2002) Incidence of nutritional risk and causes of inadequate nutritional care in hospitals. Clin Nutr 21, 461-468.

4. Rasmussen HH, Kondrup J, Staun M, Ladefoged K, Kristensen H \& Wengler A (2004) Prevalence of patients at nutritional risk in Danish hospitals. Clin Nutr 23, 1009-1015.

5. Sullivan DH (1999) Protein-energy undernutrition among elderly hospitalized patients. A prospective study. JAMA 281, 2013-2019.

6. Edington J, Boorman J, Durrant ER, et al. (2000) Prevalence of malnutrition on admission to four hospitals in England. Clin Nutr 19, 191-195.

7. Bacquer de D, Backer de G, Cokkinos D, Keil U, Montaye M, Östör E, Pyörälä K \& Sans S for EUROASPIRE II Study Group (2004) Overweight and obesity in patients with established coronary heart disease: are we meeting the challenge? Eur Heart $J$ 25, 121-128.

8. Lorgeril M, Renaud S, Mamelle N, Salen P, Martin J-L, Monjaud I, Guidollet J, Touboul P \& Delaye J (1994) Mediterranean $\alpha$-linolenic acid-rich diet in secondary prevention of coronary heart disease. Lancet 343, 1454-1459.

9. Ornish D, Scherwitz LW, Billings JH, et al. (1998) Intensive lifestyle changes for reversal of coronary heart disease. JAMA 280, 2001-2008.

10. American Heart Association (2002) AHA Guidelines for primary prevention of cardiovascular disease and stroke: 2002 update. Circulation 106, 388-391.

11. Pedersen AN \& Ovesen L (2000) Dietary recommendations for institutions in Denmark. 3rd ed, pp. 59-63. Søborg, Denmark: Fødevaredirektoratet.

12. Mathey MF, Vanneste VGG, de Graff C, de Groot LC \& van Staveren WA (2001) Health effect of improved meal ambience in a Dutch nursing home: a 1-year intervention study. Prev Med 32, 416-423.

13. Mathey MF, Siebelink E, de Graff C \& van Staveren WA (2001) Flavour enhancement of food improves dietary intake and nutritional status of elderly nursing home residents. $J$ Gerontol Med Sci 56, 200-205.

14. Nielsen MA, Biltz C, Freil M, Gut R \& Almdal TP (2004) Menu composition of evening meals increases energy and protein intake in patients with low nutritional intake and reduces waste. Ugeskr Lager 166, 267-270.

15. Pedersen UP (2005) Nutritional care: the effectiveness of actively involving older patients. J Clin Nurs 14, 247-255.

16. Barton AD, Beigg CL, Macdonald IA \& Allison SP (2000) A recipe for improving food intakes in elderly hospitalized patients. Clin Nutr 19, 451-454.

17. Almdal T, Viggers L, Beck AM \& Jensen K (2003) Food production and wastage in relation to nutritional intake in a general district hospital - wastage is not reduced by training the staff. Clin Nutr 22, 47-51.

18. Kondrup J, Allison SP, Elia M, Vellas B \& Plauth M (2003) ESPEN Guidelines for Nutrition Screening 2002. Clin Nutr 22, 415-421.

19. World Health Organization (1997) Obesity: Prevention and Managing the Global Epidemic. Report of a WHO Consultation on Obesity. Geneva, 3-5 June 1997. Geneva: WHO.

20. World Health Organization (1985) Energy and Protein Requirements. Joint FAO/WHO/UNU Expert Consultation. WHO Technical Report Series no. 724, pp. 71-79. Geneva: WHO.

21. Johansen N, Kondrup J, Plum LM, Bak L, Nørregaard P, Bunch E, Bærnthsen H, Andersen JR, Larsen IH \& Martinsen A (2004) Effect of nutritional support on clinical outcome in patients at nutritional risk. Clin Nutr 23, 539-550.

22. Dupertuis YM, Kossovsky MP, Kyle UG, Raguso CA, Genton L \& Pichard C (2003) Food intake in 1707 hospitalised 
patients: a prospective comprehensive hospital survey. Clin Nutr 22, 115-123.

23. Allison SP (2003) Hospital food as treatment. Clin Nutr 22, 113-114.

24. Beck AM, Balknäs UN, Fürst $\mathrm{P}$, et al. (2001) Food and nutritional care in hospitals: how to prevent undernutrition report and guidelines form the Council of Europe. Clin Nutr 20, $455-460$.

25. Gall MJ, Grimble GK, Reeve NJ \& Thomas SJ (1998) Effect of providing fortified meals and between-meal snacks on energy and protein intake of hospital patients. Clin Nutr 17, 259-264.

26. Mosca L, Jones WK, King KB, Ouyang P, Redberg RF \& Hill $\mathrm{MN}$, for the American Heart Association Women's Heart Disease and Stoke Campaign Task Force (2000) Awareness, perception, and knowledge of heart disease risk and prevention among women in the United States. Arch Fam Med 9, 506-515.

27. Naudziunas A, Jankauskiene L, Kalinauskiene E \& Pilvinis V (2005) Implementation of the patient education about cardiovascular risk factors into a daily routine of the cardiology unit of the hospital. Prev Med 41, 570-574.

28. Aquilani R, Boni R \& Verdiroso S (2002) An organizational model to translate nutritional recommendations into routine clinical practice in secondary prevention of coronary artery disease. Prev Med 34, 138-143.

29. World Health Organization (2003) Diet, Nutrition and the Prevention of Chronic Diseases. Report a Joint WHO/FAO Expert Consultation. Geneva, 28 January to 1 February 2002. Geneva: WHO. 